\title{
Role of human capital on economic growth : A case study of Pakistan
}

\author{
Farrukh Shahzad ${ }^{1,2,3}$ \\ ${ }^{1}$ M. Phil./MS Management Sciences, Lahore Leads University, Lahore, Pakistan \\ ${ }^{2}$ B. Com (HONS)/ M.Com Finance, Hailey College of Commerce, PU, Lahore \\ ${ }^{3}$ Retail Bank Officer (CS Manager, Branch Supervisor), United Bank Ltd \\ E-mail: farrukh.hailian@gmail.com
}

\begin{abstract}
The study observes the role of human capital formation on economic growth in Pakistan by utilized the secondary data form the period of 1990 to 2013. The study clearly revealed that education enrollment index (Proxy of human capital) health (IMR) and physical capital (FGCF, IGR) are keys to boost the economic growth of Pakistan. Data manipulated through least square multiple regression models by using E-view. The main variable human capital (Education Enrollment Index) has a positive significant impact on dependent variable GDP so it established that enrollment in education preferred for growth of the Pakistani economics and results are robust. Gross fix capital formation (GFCF) has positive significant impact on dependent variable furthermore investment growth rate (IGR) has highly significant and positive impact on GDP. There are negative but significant relationship between Infant Mortality Rate and consumer price index with gross domestic product of Pakistan respectively. These results indicate that both health and education sector should be required highly attention to sustain the economic growth of Pakistan.
\end{abstract}

Keywords: Human Capital; Economic Growth; IMR; IGR; GFCF.

\section{Introduction}

A country like Pakistan which is listed in underdeveloped countries, a gigantic extent of populace is dwelling underneath the national poverty line. It is normally said that through financial development, we can shorten unemployment and poverty yet the circumstances is diverse in the event of Pakistan. In Pakistan, we can't decrease the poverty through just financial development. It is the need to enhance all markers of financial development. In this manner it is viewed as that putting resources into individuals quickens their individual advancement and provides for them the capacity to get freed from poverty. This obliges education and facilitation of health and also some measures of income sanctuary. Human capital is broadly acknowledged as a vital determinant of financial growth1 and the vitality of human capital gathering is unequivocally recognized in the existing exogenous and endogenous development speculations (Mankiw \& David Romer, 1992) however what is still easy to refute is that what elements ought to be considered as human capital. In the majority of the studies education or health related markers are utilized as proxy for human capital.

It is viewed as that capital and common assets are the moderate variables while human capital is a dynamic element of production. Individuals can expand capital and develop social and monetary associations. We can never create anything for monetary development, on the off chance that we can't create the aptitudes of our human. It is clear that in the event that we need to utilize different assets viably then we need to create the limit of our human through literacy proficiency, expertise improvement and by qual- ity upgrade so we may trim down unemployment and upgrade the procedure of development.

The idea of human capital alludes to the capacities and abilities of human assets of a country, moreover human capital development alludes to the methodology of getting and expanding the number of individuals who have the abilities, education, instruction and experience that are discriminating for economic development and growth. In this manner, interest in education and health are considered as human capital advancement. This paper analyses the interaction between human capital what's more monetary development whereby human capital is seen as the whole of the investment in education and health. Despite the fact that it is evident that there are connections between human capital and income (GNP), the interconnections between the particular parts of human capital (education and health) and GNP are of broadened nature. Education - particularly in its subjective design, in the same way as the quantity of different sorts of degrees or utilized scholarly staff in the business and less in its quantitative manner, such as schooling or enrolment numbers - is said to be an explanative variable for GNP, while health acts in an alternate mode.

Todaro, (2002) Mostly the idea of Human Capital is utilized for Education, skill improvement, health and different limits of individuals that can improve their efficiency furthermore effectiveness Singh, (1999) human capital and financial improvement both are interconnected to one another for some extra premise. Moreover, it is likewise important for Government to use extra sums on Education and health segment. By human capital we consider procured mental and physical capacity of individuals through education, aptitude advancement, preparing, medicinal services and movement of some otherworldly systems like yoga 
Ali, Farooq, \& Chaudhry, (2012) after the independence of Pakistan in 1947, the government provided for its regard for develop human and physical capital in Pakistan. Without precedent for history, Zulfiqar Ali Bhutto, the Prime Minister of Pakistan offered consideration regarding the education segment furthermore manpower planning. For this reason, he chose to nationalize diverse areas of economy including Education. He attempted to give free education to all the populace of Pakistan.

Human capital arrangement has an integral part for the improvement of society. This is extremely discriminating circumstance in Pakistan that regardless of critical development rate, the markers of human capital are not tasteful. Very nearly all monetary pointers that can measure the circumstance of human improvement are low in Pakistan i.e. education rate, enrolment rate at school level, facilities of health and clean water and so forth. Amid the past period, all the amassing of government stayed in the interest in physical capital just, while government overlooked the human capital part. Because of this absence of interest in human capital, today the result is as unemployment, high poverty level, and absence of education and shortfall of power sector. In this manner to handle this issue we explored the effect of interest in Human capital on the growth of economy in Pakistan.

\section{Literature review}

From the early 1990s, different studies have endeavoured to distinguish the determinants of economic growth; long-run development is endogenous as opposed to exogenous (Romer, 1986; Lucas, 1988; Mankiw N. R. 1992). Lucas (1988) elucidation of human capital appears to be closer to populace wide education - a social action not specifically identified with the learning on the outskirts of science and innovation as contended by Romer (1986). The assurance of education to economic advancement has essentially depended on cross-country evaluations of gross enrolment rates or average years of schooling, which may be grossly lacking if rates of return to interest in education or nature of education vary considerably over the countries. The frail connection between development and increments in instructive fulfilment over the countries is seen by Benhabib, (1994) and Pritchett, (1997). Utilizing board information, Caselli, (1996) reveal a negative and significant connection between yield development and secondary enrollment ratio. Knowles, (1995) find education is not measurably significant in a scope of models that include base period output per capita and life expectancy.

Education which is most likely the most imperative determinant of human capital (Bergheim, 2005) influences the yield through different channels. It expands learning which serves to create more yield in moderately smaller time furthermore it is intuitionally proposed that an instructed individual could learn much quicker. Increment in the level of instruction additionally heads towards better health because of an increment in the attention to the banquet of sound living, which thus increments the yield. Besides, training additionally upgrades the work energy support in an economy especially in case of female participation and yield builds further, because of the higher work power investment rate. Alongside Education, the part of experience is additionally imperative in profit growth. Encounter for the most part decreases the possibilities of mistakes and expands the yield in a given time period.

Bils, (2000) said that countries which have high enrolment rate in schools can attain more development in per capita income. High enrolment rate in education causes quick exaltations in level of profit. The results have affirmed that education has a long run and huge association with development. They proposed that advance in education gauges will upgrade the benefit furthermore influence the development over the long haul.

Abbas, (2001) decided experimentally the part of human capital in development of economy. A complete investigation of two developing countries i.e. Pakistan and Sri Lanka was made. He utilized the standard development bookkeeping technique with human capital detailed and production function in which Gross Domestic Product (GDP) was the dependent variable. Along these lines, general experimental proof of the study demonstrated that human capital assumed a significant part in the development of the economies for developing countries particularly for these two nations.

Ashton, (2002) broke down that human capital was useful in development process by empowering the development of some different variables particularly interest in physical capital which is viewed as fundamental for the country. It is viewed as that human capital has positive connection with the physical capital development.

Amjad, (2005) concentrated on those variables that clarify Pakistan's relative development execution. He looked especially at the part of contrasts in the nature of human capital arrangement. The cross-country exact results recommended that collection of physical capital and changes in the nature of organizations have noteworthy results as far as attaining higher development rate yet that better education and human services have likewise a noteworthy effect on growth of economy.

\section{Data source and methodology}

Secondary source of data used for conduct of this study. Panel data from the period of 1990 to 2013 selected. The source of data for this study is attained from World Bank Indicator, Pakistan economic survey (various years) and State Bank of Pakistan (SBP). To scrutinize the association between human capital and economic growth used Ordinary Least Squares (OLS). In this study GDP used as dependent variable whereas EEI, GFC, IMR, FDI and CPI used as explanatory variables. This model will be tested for autocorrelation regression error in this equation by Durban Watson (DW) test statistic.

\section{Variables conceptions}

This segment is saved to concentrate on the considered variables in our investigation of human capital development. These variables have been chosen keeping in view their relative significance on hypothetical and exact ground. The decision of variables is reliable with the decision made by some different scientists (Mankiw 1992, Romer 1990)

The Elucidation of attempted variables and their proposed Impact is defined as follows:

\subsection{Gross domestic product (GDP)}

The gross domestic product (GDP) is one the primary indicators used to gauge the health of a country's economy. It represents the total dollar value of all goods and services produced over a specific time period - you can think of it as the size of the economy. Usually, GDP is expressed as a comparison to the previous quarter or year. We used GDP as dependent variable.

\subsection{Education enrolment index}

The human capital proxy that we practice in our study is 'school enrolment ratio'. It dealings the number of students enrolled at a detailed grade level. Barro \& Lee, (2000) and Mankiw (1992) have also used this proxy in their study. In this study the method used by Barro and Lee (2000) for generation of human capital has been used and we have used 'Education Enrolment Index (EEI)' as a proxy for Human Capital.

$\mathrm{EEI}=(\mathrm{PPED}+5 \mathrm{EDt}+8 \mathrm{EDt}) /$ Population

Where:

EEI $=$ Education Enrolment Index

PPEDt $=$ Enrolment of primary education

$5 \mathrm{EDt}=$ Enrolment of middle education

$8 \mathrm{EDt}=$ Enrolment of secondary education 


\subsection{Gross fixed capital formation}

Gross Fixed Capital Formation figures the estimation of acquisitions of new or existing altered resources by the legislatures and households in the economy. Variances in this marker are considered to show something about future business exercises and the summary of monetary improvement. In Harrod-Domar model, the development rate of income will be emphatically identified with sparing degree and capital arrangement. Along these lines, we can say that the more a nation has the capacity spare and contribute out of given national salary, the more noteworthy will be the development of that national income.

\subsection{Infant mortality rate}

The baby death rate is computed by evaluating aggregate number of kids dying under a year of age partitioned by the aggregate number of kids conceived in that year. One of the health marker 'the infant mortality rate' is additionally called the 'infant death rate' is an essential measure to gauge the welfare of babies, kids and pregnant females. The two-way causality exists between income level and health status, is relied upon to status of the populace considering the level of development of the nation's horrible residential item. It is said that health is impacted by income level and then again health status impacts the level of income. It found that health variables impact per capita GDP decidedly while for every capita GDP, thus, affects health variables (e.g. IMR) Positively.

\subsection{Consumer price index}

Inflation in Pakistan has been assessed as yearly rate change of average consumer price index. CPI swelling which is an independence variable of our study has numerous preferences of utilizing it as a part of the model as opposed to other swelling rates. Some economists proposed utilizing CPI swelling as a part of the model because of the reason that it diminishes the likelihood of negative relationship between inflation and growth rates (Sarel, 1996). An alternate playing point of utilizing it as a part of the model is that, CPI records are free of output volume, so its utilization in the model prevents correlation issues to happen in the model. Investment in human capital is a noteworthy variable that helps long run financial development. Numerous models of development and inflation have taken human capital in the type of an endogenous variable. These models of development show unbiased or negative effect of inflation on investment in human capital.

\subsection{Investment growth rate (IGR)}

We used IGR, as a data advancement marker in the Multiple Regression Model, itemized in examination. Data game plan covers the period from 1990 to 2013 and is taken from the World Bank IGR is measured in Percentage. It is used as self-governing variable in the proposed model and found negative impact on economic growth.

\section{Specification of data}

In the stated model, we utilize GDP as dependent variable while EEI, GFCF, IMR, IGR and CPI are explanatory variables. Subsequent Mankiw, Romar, \& Weil (1992), our econometric model of the designated variables utilized in this study is certain as follows:

$$
\begin{gathered}
\text { LGDP }=\beta_{0}+\beta_{1}(\text { LEEI })+\beta_{2}(\text { LGFCF })+\beta_{3}(\text { LIMR })+\beta_{4}(\text { IGR }) \\
+\beta_{5}(\text { CPI }+\mu
\end{gathered}
$$

Where

LGDP $=$ Log (Gross Domestic Product)

LEEI $=$ Log (Education Enrolment Index)

LGFCF = Log (Gross Fix Capital Formation)

LIMR $=$ Log (Infant Mortality Rate)
IGR $=$ Investment Growth Rate

$\mathrm{CPI}=$ Consumer Price Index

$\mu=$ Error Term

\section{Discussions and results}

In this segment we will display the measurable and econometric information examination. Descriptive statistics is the order of portraying the principle quantitative gimmicks of information utilized as a part of study. They give uncomplicated and straightforward synopses about the information and the measures. It is utilized for quantitative examination of information. Clear measurements of the variables of our model are given in after table.

Table 1: Descriptive Statistics of the Variables

\begin{tabular}{lllllll}
\hline \multicolumn{7}{c}{ Table 1: } \\
\hline Lean & 4.13 & 11.45 & 2.26 & 86.49 & 1.19 & 9.16 \\
Median & 4.13 & 10.05 & 2.95 & 85.40 & 0.82 & 9.28 \\
Maximum & 7.70 & 27.86 & 19.90 & 106.10 & 3.66 & 20.28 \\
Minimum & 1.01 & -0.34 & -6.26 & 69.00 & 0.38 & 2.91 \\
Std. Dev. & 1.93 & 7.29 & 6.32 & 11.42 & 0.90 & 4.08 \\
Skewness & 0.29 & 0.55 & 0.85 & 0.16 & 1.64 & 0.48 \\
Kurtosis & 2.25 & 2.78 & 3.85 & 1.79 & 4.57 & 3.55 \\
Jarque-Bera & 0.91 & 1.26 & 3.62 & 1.56 & 13.26 & 1.24 \\
Sum & 99.12 & 274.81 & 54.45 & 2075.80 & 28.74 & 220.01 \\
Sum Sq. Dev. & 86.35 & 1222.85 & 921.33 & 3002.93 & 19.02 & 384.06 \\
& & & & & & \\
Observations & 24 & 24 & 24 & 24 & 24 & 24 \\
\hline
\end{tabular}

Note: All the estimations are carried out by E-views

In the Table 1, the comprehensive eloquent analysis is accomplished. Our data contains of 24 years of annual observation from 1990 to 2013. The descriptive statistics revelations that the average of gross domestic product is 4.12024 with standard deviation of 1.93 the ordinary education enrolment index is 11.45 with standard deviation of 7.29.

The average of GFCF is 2.26 with the standard deviation 6.32 and the mean of IMR is 86.49 with the standard deviation of 11.42 moreover IGR and CPI means are 1.19 and 9.16 with the standard deviation of .90 and 4.08 respectively.

Relationship coefficient demonstrates the level of straight relationship between two variables. A Correlation Matrix is a table which demonstrates all conceivable relationship coefficients between a set of variables. Relationship network of the variables of our model is given in after table.

Table 2: Correlation Matrix

\begin{tabular}{lllllll}
\hline & GDP & EEI & GFCF & IMR & IGR & CPI \\
\hline GDP & 1.000 & & & & & \\
EEI & 0.292 & 1.000 & & & & \\
GFCF & 0.491 & 0.828 & 1.000 & & & \\
IMR & 0.050 & 0.110 & 0.164 & 1.000 & & \\
IGR & 0.096 & 0.510 & 0.383 & -0.312 & 1.000 & \\
CPI & -0.239 & 0.499 & -0.071 & -0.056 & 0.313 & 1.000 \\
\hline
\end{tabular}

Note: All the estimations are carried out by E-views

\subsection{Unit root test results}

Non stationary of time plan data has often been considered as an issue in test investigation. Working with non-stationary variables prompts spurious backslide results, from which further actuation is useful to no end. Therefore, it is foremost to test the stationary of all course of action entering in the model. The ADF test was used to test the stationary of the course of action. The invalid speculation was that the variable under investigation has a unit root, against the alternative that it doesn't. The outcomes of the test for the variables are presented in Figure already in variable conception.

The results reported in Table 3 are finished with example and catch. Results demonstrated that all plan show non stationary in levels. As being what is indicated, the invalid hypothesis that each of the time plan has a unit root can't be dismisses. Then again, there is no verification of a unit root when the plans are at first 
contrasts. The no stationary speculation was discharged in all cases. It suggests that all the variables under investigation are stationary from the earliest starting point refinement at $1 \%$ level of centrality except for LK which was stationary at $5 \%$ level of diacritical's, as can be understood from table 3 .

Table 3: Results of ADF Test for Non Stationary

\begin{tabular}{lllll}
\hline \multirow{2}{*}{ Variables } & \multicolumn{2}{l}{ ADF test at level } & \multicolumn{2}{c}{ ADF test at 1st difference } \\
& Calculated & lag & Calculated & lag \\
\hline LGDP & 2.49 & 1 & $4.01^{*}$ & 1 \\
LEEI & 2.15 & 1 & $4.12^{* *}$ & 1 \\
LGFCF & 2.56 & 1 & $4.21^{*}$ & 1 \\
LIMR & 2.68 & 1 & $6.32^{* *}$ & 1 \\
IGR & 2.71 & 1 & $5.19^{* *}$ & 1 \\
CPI & 2.89 & 1 & $4.35^{*}$ & 1 \\
\hline
\end{tabular}

Note: - The asterisks (*) and (**) indicates statistical significance at the 5 percent and 1 percent significance level.

\subsection{Multiple regression result}

Table 4: Regression Results

\begin{tabular}{|c|c|c|c|c|}
\hline \multicolumn{5}{|c|}{ Dependent Variable: LGDP } \\
\hline \multicolumn{5}{|c|}{ Method: Least Squares } \\
\hline \multicolumn{5}{|c|}{ Date: $01 / 04 / 15$ Time: $15: 27$} \\
\hline \multicolumn{5}{|c|}{ Sample: 19902013} \\
\hline \multicolumn{5}{|c|}{ Included observations: 24} \\
\hline Variables & Coefficient & Std. Error & t-Statistic & Prob. \\
\hline $\mathrm{C}$ & 8.768599 & 6.304256 & 1.390902 & 0.0000 \\
\hline LEEI & 385.0649 & 130.2547 & 2.956245 & 0.0060 \\
\hline LGFCF & 385.2239 & 146.2586 & 2.633854 & 0.0094 \\
\hline LIMR & -8.051367 & 3.510573 & -2.293462 & 0.0048 \\
\hline IGR & 4.768191 & 2.352269 & 1.890886 & 0.0003 \\
\hline CPI & -384.9886 & 151.2765 & -2.544933 & 0.0001 \\
\hline \multicolumn{2}{|c|}{$\mathrm{R}$ Square $=0.38$} & \multicolumn{3}{|c|}{ Mean dependent var $=4.130245$} \\
\hline \multicolumn{2}{|c|}{ Adjusted R2 $=0.33$} & \multicolumn{3}{|c|}{ S.D. dependent var $=1.937683$} \\
\hline \multicolumn{2}{|c|}{ F-statistic $=8.853168$} & \multicolumn{3}{|c|}{ Sum squared resid $=60.35815$} \\
\hline \multicolumn{2}{|c|}{ Prob $($ F-statistic $)=0.007569$} & \multicolumn{3}{|c|}{ Durbin-Watson $=0.98135$} \\
\hline
\end{tabular}

Note: All the estimations are carried out by E-views

The proposed model precise results are portrayed by the above table. The incline coefficients of EEI in the OLC researches have positive effect on GDP though two variables FGCF and IGR have also positive effect on GDP respectively. IMR and CPI have the negative and significant impact on GDP. The Adjusted R square is . 38 which explains $26 \%$ variety in the dependent variable (GDP) represented by the explanatory variables EEI, GFCF, IMR, IGR and CPI. The estimation of Durbin Watson is .9813 which implies that there is sure autocorrelation of leftover.

The adjusted $\mathrm{R}$ square is .33 which explains $33 \%$ variation in the dependent variable (LGDP) accounted for by the explanatory variables LEEI, LGFCF, LIMR, IGR and CPI. The value of Durbin watson is .9813 which means that there is positive autocorrelation of residual.

\section{Suggestion and conclusion}

This study has conducted an endeavour to give the experimental affirmation on the relationship between human capital and economic development. The consequences of this study revealed that there is long run relationship between economic development, education enrolment, investment growth rate (IGR), fix capital formation and inflation CPI. There is a positive significant impact of Education enrolment on Economic Growth: it clearly means that if increment in education enrolment then definitely develops the economy of country. Furthermore the gross domestic fix capital formation has also positive and significant impact on economic growth.

Results also revealed that investment growth rate (IGR) has negative impact on growth of economy of Pakistan and this happened due to lack of investment in Pakistan. The capital investment is low in Pakistan which diminishes new limit for the interest for merchandise. Low request and yield of merchandise further dis- hearten interest in new apparatus. So because of low investment, the IGR has negative impact on financial development. In addition, in Pakistan, for the most part venture uses by government have completed for non-profitable purposes. This is additionally a significant purpose behind the negative effect of venture development rate on financial development. For conducted this study some of the following suggestion should be a positive impact on economic growth of Pakistan.

- As enhanced engineering and effectiveness is the components key to monetary development so more consideration ought to be given to cutting edge engineering, preparing and ability improvement of human capital.

- Government ought to build openings for work for individuals so the expanding populace could enhance the financial development of nation and turn into a mean of development as opposed to an impediment in the method for financial improvement of the nation.

- An expansive offer of government consumptions goes in the method for exchange instead of the improvement exercises. Government ought to make measures to ease destitution with the goal that the soil grown foods of government consumptions could be attained to.

- Expansion ought to be overseen in light of the fact that high or flighty swelling rates are seen as ruinous for a general economy of a nation.

- Interest in capital ought to be expanded which will improve new limit for the interest for merchandise. Expanded request and yield will help interest in new capital hardware which will further help to keep up the development in the economy by climbing long run total supply.

- Government ought to build the enrolment degree at all instruction levels. Instruction helps monetary improvement through the generation of information and aptitudes. It likewise expands work benefit and personal satisfaction, strengthens common society what's more empowers popular government.

- Government ought to build opportunities for the instruction of female. Training of female will create youngster wellbeing. This will lower baby death rate. It helps in profit and financial development in late era as well as in the cutting edge.

Pay imbalance ought to be lessened through fitting government arrangements for monetary development in light of the fact that there is a two-way positive relationship between a more square with dissemination of pay and a higher rate of monetary development.

\section{References}

[1] Abbas, Q. (2001). Endogenous Growth and Human Capital: A Comparative Study of Pakistan and Sri Lanka. The Pakistan Development Review, 40(4), 987-1007.

[2] Ali, S., Farooq, F., \& Chaudhry, I. S. (2012). Human Capital Formation and Economic Growth in Pakistan. Pakistan Journal of Social Sciences (PJSS), 32(1), 229-240.

[3] Amjad, R. (2005). Skills and Competitiveness: Can Pakistan Break Out of the Low-level Skills Trap? The Pakistan Development Review, 44(4), 387-409.

[4] Ashton, D. a. (2002). Supporting Workplace Learning for High Performance Working. A Research Report for International Labor Organization, Geneva.

[5] Barro \& Lee. (2000). International Measures of Schooling Years and Schooling quality. American Economic Review, 82(2), 218-223.

[6] Benhabib, J. a. (1994). The Role of Human Capital in Economic Development: Evidence from Aggregate Cross-Country Data'. Journal of Monetary Economics, 34(2), 143-174. http://dx.doi.org/10.1016/03043932(94)90047-7.

[7] Bergheim, S. (2005). Current Issue. Frankfurt am Main, Germany. Deutsche Bank Research,

[8] Bils, M. a. (2000). Does Schooling cause Growth? American Economic review, 90(5), 1160-1183. http://dx.doi.org/10.1257/aer.90.5.1160.

[9] Caselli, F. E. (1996). Reopening the convergence debate: a new look at cross-country growth empirics', Journal of Economic Growth, 13, 363-389. http://dx.doi.org/10.1007/BF00141044. 
[10]Knowles, S. O. (1995). Health Capital and Cross-country variation in income per capita in Mankiw-Romer-Weil Model'. Economics Letters, 48, 99-106. http://dx.doi.org/10.1016/0165-1765(94)00577-O.

[11]Lucas, R. (1988). On the Mechanics of Economic Development. Journal of monetary economics, 22, 3-42. http://dx.doi.org/10.1016/03043932(88)90168-7.

[12] Mankiw, N. G., \& David Romer, a. D. (1992). A Contribution to the Empirics of Economic Growth. Quarterly journal of Economics, 107, 407-437. http://dx.doi.org/10.2307/2118477.

[13]Mankiw, N. R. (1992). A contribution to the empirics of economic growth. Quarterly Journal of Economics, 107, 407-437. http://dx.doi.org/10.2307/2118477.

[14]Mankiw, N., Romar, G., \& Weil, D. (1992). A Contribution to the Empirics of Economic Growth. The Quarterly Journal of Economics, 107(2), 407-437. http://dx.doi.org/10.2307/2118477.

[15]Pritchett, L. (1997). Where Has All the Gone?', The World Bank, Washington DC,. Policy Research Working Paper, 1581.

[16]Romer, P. (1986). Increasing Returns and Long-Run Growth. Journal of politicle Economy, 94(5), 1002-1037. http://dx.doi.org/10.1086/261420.

[17] Sarel, M. (1996). Nonlinear Effects of inflation on Economic Growth IMF Staff Paper, 43(3). http://dx.doi.org/10.2307/3867357.

[18]Singh, K. (1999). Rural Development: Principles, Policies and Management, (2nd Edition Ed.). New Delhi, India: Sangha Publications.

[19]Todaro, M. (2002). Economic Development. (Vol. 8th Edition). New York: Longman. 